\title{
Rursus
}

m Ruksus

Poiétique, réception et réécriture des textes antiques

$2 \mid 2007$

Le modèle animal (II)

\section{Les structures d'un imaginaire tragique dans les Annales de Tacite}

Résumé de mémoire de littérature latine sous la direction de M. E. Delbey (2004-2006)

\section{Emilie Hegelen}

\section{(2) OpenEdition}

Journals

Édition électronique

URL : http://journals.openedition.org/rursus/150

DOI : $10.4000 /$ rursus. 150

ISSN : 1951-669X

Éditeur

Université Nice-Sophia Antipolis

Référence électronique

Emilie Hegelen, «Les structures d'un imaginaire tragique dans les Annales de Tacite », Rursus [En ligne], 2 | 2007, mis en ligne le 16 mars 2011, consulté le 22 septembre 2020. URL : http://

journals.openedition.org/rursus/150; DOI : https://doi.org/10.4000/rursus.150

Ce document a été généré automatiquement le 22 septembre 2020.

Rursus 


\title{
Les structures d'un imaginaire tragique dans les Annales de Tacite
}

\author{
Résumé de mémoire de littérature latine sous la direction de M. E.
} Delbey (2004-2006)

\section{Emilie Hegelen}

1 A la lecture des Annales de Tacite, historien latin de l'époque impériale, nous avons décelé au cours du récit historique, une tendance à se laisser influencer par le genre tragique, du fait même que le sujet de ce dernier dépendait essentiellement du pouvoir devenu absolu depuis le principat d'Auguste, ainsi que des intrigues politiques qui en découlaient. Soutenus par une remarque du poète dramatique Racine qui note, dans la préface de Britannicus, relatant un épisode présent également dans les Annales, qu'il s'est inspiré du "plus grand peintre de l'Antiquité », c'est-à-dire de Tacite, nous nous sommes intéressés aux structures d'un imaginaire tragique dans les Annales.

2 Nous nous sommes penchés tout d'abord sur l'esprit tragiques des intrigues de palais, intrigues qui constituent la majeure partie de l'œuvre de Tacite consacrée aux empereurs de la dynastie julio-claudienne. Dans un premier temps nous avons voulu démontré que le pouvoir était à la base même d'un espace tragique dans les Annales, et que de ce fait le tragique émanait du sujet historique lui-même choisi par Tacite. En effet, le noyau de l'histoire romaine, ainsi que le destin de l'Empire n'est autre que le pouvoir qui est passé aux mains d'un seul homme. Dès lors se forme autour de cette notion un espace tragique, car celle-ci engendre non seulement l'autorité, mais également la convoitise de tous ceux qui s'en approchent et recherchent par tous les moyens de posséder la place de l'empereur, d'occuper l'espace clos et sans issu du pouvoir. C'est ainsi que se mettent en place des relations fondamentales et exclusives entre les personnages historiques, l'autorité et la convoitise, relations qui organisent des scènes récurrentes au cours de l'histoire de l'Empire romain, proches de celles des tragédies, telles que le fratricide ou le parricide. Le pouvoir absolu et l'ambition de plusieurs sont au fondement de nombreuses tragédies grecques et latines, qui mettent en scène un tyran voulant à tout prix conserver son espace pour lui seul, et qui n'envisage en aucun cas de le partager. Ce sont des tragédies du pouvoir que Tacite met 
en scène, où d'une part, les différents prétendants sont prêts à éliminer les obstacles de leur ascension, et où d'autre part, celui qui possède le pouvoir tient à le garder pour lui seul. L'espace tragique des Annales se met en place à partir d'une crise d'espace, où il n'y a pas de place pour deux. Le pouvoir suscite des passions, telle que l'orgueil, l'ambition, ou la haine, qui amènent au crime et à la mort, qui devient l'élément caractéristique du pouvoir et l'indice même du tragique dans cet espace. En outre, ces passions font des personnages historiques de véritables figures tragiques traditionnelles, animées par des passions proches du furor; par cette dialectique, ils retrouvent leur identité et leur personnalité propre dans toute sa profondeur.

En effet, dans un second temps, nous nous sommes intéressés à la manière dont Tacite traite les personnages historiques de l'Empire. Ce dernier met en scène ses personnages et les montre en action, non seulement parce qu'ils ont à remplir un rôle politique, mais parce qu'ils font semblant de jouer ce rôle d'acteur politique et transforment ainsi l'histoire en une tragédie du pouvoir. Notre historien se fait poète tragique et metteur en scène, dans la mesure où il privilégie des portraits qui sortent de l'action elle-même, capables de dévoiler non seulement le jeu des personnages au sein de l'histoire, mais également leur complexité dans leurs rapports avec autrui, ainsi que la profondeur de leurs caractères. Pour cela, Tacite n'hésite pas à user de moyens dramatiques, tels que les discours et les dialogues, la description de la gestuelle et du comportement des personnages, dans un décor au service même de l'action, d'où la présence dans le récit des Annales de véritables scènes dramatiques et pathétiques, dignes d'une véritable tragédie.

4 Dans un deuxième volet de notre étude, nous nous sommes interrogés sur les signes d'une théâtralisation du récit historique des Annales, en analysant les éléments dramatiques et pathétiques permettant une mise en scène tragique de certains événements historiques des Annales. Le fait de privilégier la présentation en acte de ses personnages, essentiellement autour du pouvoir, amène Tacite à avoir recours à des discours, au sein même d'un dialogue, ayant un effet dramatique sur le cours du récit, ainsi que la mise en scène de gestes, susceptibles de l'emporter sur le récit lui-même. Tacite semble par moment faire voir le récit sur un mode dramatique, non seulement pour le rendre plus vivant et davantage plaisant, mais également pour émouvoir le lecteur devenant alors spectateur, et ce à l'aide de scènes dramatiques et pathétiques. L'analyse de ces scènes dramatiques et pathétiques nous a permis de lever en partie le voile sur la perception tacitéenne de l'histoire puisque Tacite, même s'il paraît demeurer totalement objectif, laisse percer quelques rayons de subjectivité en se faisant metteur de l'histoire.

5 Enfin, le tragique ne correspond pas uniquement, au niveau esthétique, à la dramatisation, mais il renvoie également à une réflexion philosophique sur la place de l'homme dans un ordre du monde voulu par les dieux, la nature de son action et sa liberté par rapport à une fatalité qui établit un destin, et notamment le destin de Rome. En effet, ce qui fait que Tacite se rapproche du genre tragique, c'est qu'en tant qu'historien, il s'interroge sur les causes et les conséquences des différents événements et tente de les expliquer. Appartenant à une civilisation imprégnée par la religion polythéiste, mais une religion qui a connu des périodes de doutes et de crises, comme à la fin de la République, il a le sentiment de la présence d'une volonté divine, à la base d'un ordre du monde que l'homme se doit de respecter, sous peine d'exciter la colère divine; toutefois, il doute parfois de la valeur des manifestations des dieux. Aussi, 
Tacite observant le penchant vers la tyrannie du principat, dû en grande partie au mauvais caractère des princes, qui cherchent, avant l'intérêt de l'Etat, à assouvir leurs passions, s'interroge-t-il sur les destins de l'Empire romain, la nature de la volonté divine, ou plus précisément d'une puissance transcendante, contre laquelle l'homme, même s'il tente et pense affirmer sa liberté, accomplit le destin selon un mouvement fatal. Tacite recherche la nature complexe et parfois désarmante de cette transcendance, qui peut-être s'assimile, dans les Annales et l'histoire tacitéenne dans son ensemble, au Pouvoir lui-même, dans l'attente d'un bon empereur, prêt à endosser ce rôle et à le jouer avec justesse et qui se pervertit s'il échoit à un mauvais acteur de l'histoire.

6 Ainsi, Tacite utilise le tragique au service même de l'histoire comme moyen d'explication du cours de l'histoire et du destin de l'Empire romain, ainsi que des causes de la chute de la dynastie julio-claudienne. C'est par là-même qu'il révèle sa position par rapport à un éventuel destin de Rome, sa vision "pessimiste » en dévoilant une conscience tragique de l'histoire à l'œuvre dans les Annales. 